\title{
Predição de ganhos genéticos e seleção de progênies de mamoeiro para resistência à pinta-preta
}

\author{
Marcelo Vivas $^{1}$, Silvaldo Felipe da Silveira ${ }^{1}$, Janieli Maganha Silva Vivas ${ }^{1}$ \& Messias Gonzaga Pereira ${ }^{2}$ \\ ${ }^{1}$ Laboratório de Entomologia e Fitopatologia, ${ }^{2}$ Laboratório de Melhoramento Genético Vegetal, Universidade Estadual do \\ Norte Fluminense Darcy Ribeiro, Av. Alberto Lamego, 2000, Parque Califórnia, 28013-602, Campos dos Goytacazes, RJ, \\ Brasil
}

Autor para correspondência: Marcelo Vivas, e-mail: mrclvivas@hotmail.com

\section{RESUMO}

Variedades crioulas constituem alternativas para a ampliação da base genética e incorporação de genes de resistência a doenças em programas de melhoramento genético de plantas. Para tanto, há necessidade de utilização de métodos de seleção capazes de explorar eficientemente o material genético disponível. Com a finalidade de selecionar progênies de meios-irmãos derivadas de mamoeiros dióicos, para a efetiva concentração de alelos que condicionam resistência à pinta-preta, testaram-se os índices de seleção de Smith \& Hazel, Pesek \& Baker, Williams e Mulamba \& Mock. A proposta de utilização de um índice visa buscar uma alternativa mais robusta na identificação de genótipos resistentes. Definiu-se a intensidade de seleção de $41,66 \%$, correspondendo ao número de dez progênies. Os índices de Mulamba \& Mock e Willians proporcionaram ganhos mais adequados para as características avaliadas quando utilizado o coeficiente de variação genético (CVg) como critério de peso econômico, sendo selecionadas as progênies 'STA-02', 'STA-04', 'STA-05', 'STA-08', 'STA-13', 'STA-15', 'STA-16', 'STA-17', 'STA-22' e 'STA-24', para compor um novo ciclo de seleção.

Palavras-chave: Asperisporium caricaee, Carica papaya, ganho genético, hibridação, seleção combinada.

\begin{abstract}
Prediction of genetic gain and progenies selection of papaya for resistance to black-spot

Landraces are alternatives for widening the genetic base and for incorporation of disease resistance genes in plant breeding programs. For this the use of screening methods capable of efficiently exploiting the available genetic material are needed. With the goal of selecting half-sib families of papaya for a favorable alleles concentration for resistance to black spot, the selection indices of Smith \& Hazel, Pesek \& Baker, Williams, and Mulamba \& Mock were tested. The proposed use of an index aims to seek a more robust alternative to identify genotypes resistant The selection intensity of $41.66 \%$ was defined, corresponding to the number of ten progenies. The indices of Mulamba \& Mock and Williams have provided gains more suitable for the evaluated characteristics when used the genetic variation coeficient $(\mathrm{CVg})$ as criterion of economic weight. This two methodologies helped select the following progenies 'STA-02', 'STA-04', 'STA-05', 'STA-08', 'STA-13', 'STA-15', 'STA-16', 'STA-17', 'STA-22' and 'STA-24', to compose a new cycle of selection.
\end{abstract}

Key words: Asperisporium caricae, Carica papaya, combined selection, genetic gain, hybridization.

\section{INTRODUÇÃO}

O mamoeiro (Carica papaya L.) é uma das fruteiras mais comuns em quase todos os países da América Tropical (Serrano \& Cataneo, 2010). Estes autores apontam os Estados da Bahia (902 mil toneladas), Espírito Santo (630 mil toneladas), Rio Grande do Norte (106 mil toneladas) e Ceará (100 mil toneladas) como principais produtores. Doenças causadas por fungos estão entre os fatores que limitam a produção e exportação de frutos de mamoeiro (Nishijima et al., 1994). Dentre estas, destaca-se a pinta-preta, causada por Asperisporium caricae (Speg.) Maubl. A pintapreta, a qual há algum tempo se atribuía importância secundária, vem se consolidando como a principal doença fúngica foliar na cultura do mamoeiro. A doença pode ocasionar perdas severas na produção, reduzindo a área fotossintética e, principalmente, depreciando frutos (Rezende \& Martins, 2005).
A seleção de genótipos resistentes se constitui em uma das alternativas mais eficientes de controle de doenças de plantas (Vivas et al., 2010, 2011, 2012). Todavia, em mamoeiro, a resistência total (resistência qualitativa, ocasionada por genes maiores) à pinta-preta não tem sido observada em genótipos comerciais e/ou genótipos que já tenham passado por ciclos de seleção. Vivas (2009), avaliando a coleção de germoplasma UENF/CALIMAN, observou baixa variabilidade genética para a resistência à pinta preta entre os genótipos avaliados, evidenciando assim a necessidade de ampliação da base genética.

Para ampliar a base genética pode-se fazer uso das variedades crioulas, especialmente na busca e incorporação de genes de resistência a fitopatógenos. Por exemplo, Theodoro (2004) identificou fontes de resistência ao crestamento bacteriano comum (Xanthomonas axonopodis pv. phaseoli), em cultivares locais de feijoeiro, coletadas em 
Santa Catarina. Ainda em feijoeiro, Medeiros et al. (2008) caracterizaram a reação de germoplasma crioulo a 12 raças de Colletotrichum lindemuthianum e determinaram que cultivares crioulas poderiam exibir resistência durável a este patógeno.

A utilização de genótipos crioulos em mamoeiro também pode ser uma alternativa para o aumento da variabilidade genética da cultura e para incorporação de alelos que conferem resistência a pinta-preta. Oliveira et al. (2010), avaliando a diversidade genética de 18 raças locais de mamoeiro do Recôncavo Baiano e 30 acessos do BAG de Mamão da Embrapa Mandioca e Fruticultura Tropical, com auxílio de marcadores microsatélites, constataram variabilidade genética adicional nos genótipos crioulos. Vivas et al. (2012) encontraram variabilidade genética entre as progênies oriundas de genótipos crioulos para resistência à pinta-preta. Pelos resultados dos parâmetros genéticos estimados, os autores concluíram que a seleção recorrente poderá ser utilizada para o avanço de geração. Para tanto, há necessidade de selecionar as melhores progênies, etapa importante em programa de seleção recorrente. A identificação de genótipos superiores exige métodos de seleção capazes de explorar eficientemente o material genético disponível, maximizando o ganho genético em relação às características de interesse.

Para a seleção simultânea de diferentes variáveis pode-se fazer uso dos índices de seleção. Essa metodologia permite gerar um agregado genotípico sobre o qual se pratica a seleção, funcionando como caráter adicional, resultante da combinação de diferentes caracteres previamente selecionados, nos quais se deseja exercer a seleção simultânea (Smith, 1936; Hazel, 1943; Williams, 1962; Vilarinho et al., 2003). Ide (2008) utilizou-se desta técnica para a seleção de híbridos de mamoeiro que agregassem alelos favoráveis a características da planta (altura, diâmetro do caule) e do fruto (número/planta, tamanho, peso, firmeza da polpa e da casca, teor de sólidos solúveis), dentre outras. Esta é a primeira vez que se usa de índice de seleção para agregar várias formas de avaliar a resistência de genótipos de mamoeiro à pinta-preta, possibilitando assim, gerar um critério de seleção mais robusto, levando-se em consideração todas as características avaliadas.

Devido à inexistência de genótipos de mamoeiro comerciais resistentes à pinta-preta, o presente trabalho tem como objetivo predizer os ganhos genéticos obtidos por diferentes índices e critérios de seleção, com a finalidade de gerar uma única variável que permita selecionar as dez melhores progênies de mamoeiro quanto à resistência a pinta-preta.

\section{MATERIAL E MÉTODOS}

Em 2010, instalou-se um experimento em blocos casualizados, com seis repetições, na Fazenda Água Limpa, Município de Mimoso do Sul (Latitude 2103'52”S,

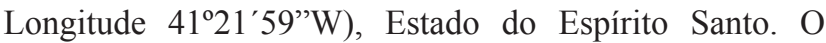
experimento foi composto de 24 progênies de mamoeiro (23 oriundas do sul do Espírito Santo e uma proveniente da Bahia) e cada unidade experimental foi composta por uma planta. Os tratamentos foram dispostos em fileira simples, no espaçamento de $2 \mathrm{~m}$ entre fileiras e $1,5 \mathrm{~m}$ entre plantas. A adubação foi conduzida conforme preconizado por Marin et al. (1995). Não houve a necessidade de realizar a inoculação artificial com A. caricae em plantas de mamoeiro.

\section{Avaliação de doença}

Objetivando selecionar as dez melhores progênies quanto à resistência à pinta-preta, avaliou-se o comportamento das progênies, considerando os diferentes componentes de resistência (características). A partir destes componentes, foi gerado um índice de forma a contemplar o conjunto das características avaliadas, possibilitando a seleção das dez progênies pretendidas. As seguintes características foram avaliadas:

i) Posição da folha que apresentou os primeiros sintomas de pinta-preta (FIS). Contou-se do ápice para a base qual folha apresentava o primeiro sintoma de doença. Considerou-se como primeira folha aquela totalmente expandida;

ii) Incidência (\%) de folhas com sintoma de pinta-preta (IPP) pela relação do número de folhas com sintomas de pinta-preta e o número de folhas total da planta;

iii) Severidade de pinta-preta na folha com a primeira flor aberta (SPP), estimada com auxílio de escala diagramática adotada por Vivas et al. (2011), com valores de 0,$2 ; 1,6 ; 3,5 ; 5,4 ; 7,6$ e $12,8 \%$ de área foliar lesionada, conforme metodologia adotada por Vivas et al. (2011);

iv) Reação das diferentes progênies quanto à resistência à pinta-preta (SSF). Esta avaliação foi efetuada na folha com a primeira flor aberta, utilizando-se a escala de notas de Santos Filho et al. (2007), que varia de 0 a 3, sendo: (0) folha sem lesão; (1) folha com até cinco lesões; (2) folha com mais de cinco lesões, limitadas a 20; e, (3) folha com mais de 20 lesões ou áreas coalescidas;

v) Reação das diferentes progênies quanto à resistência à pinta-preta, avaliada na folha com a primeira flor aberta, conforme escala diagramática de Santos \& Barreto (2003) (SSB), atribuindo-se notas que variam de 0 a 6, sendo: (0) folha sem lesão, (1) folha com até 25 lesões, (2) folha com 26 a 75 lesões, (3) folha com 76 a 150 lesões, (4) folha com 151 a 300 lesões, (5) folha com 301 a 600 lesões e (6) folha com mais de 600 lesões.

\section{Análise estatística}

No presente estudo foram feitas duas análises de variância. A primeira visou avaliar se há influencia do sexo (masculino e feminino) na manifestação da resistência à pinta-preta. Assim, visando verificar a possibilidade de variação para a resistência à doença dentro de sexo, hierarquizou-se sexo dentro de progênie. Uma segunda 
análise de variância foi realizada, considerando-se apenas efeitos de bloco e progênie, visando-se obter as matrizes de média, variâncias e covariâncias fenotípicas e genotípicas, necessárias para a estimação dos ganhos pelos índices de seleção. Os índices de seleção empregados para predizer os ganhos genéticos foram de Smith (1936) e Hazel (1943), Pesek \& Baker (1969), Williams (1962) e Mulamba \& Mock (1978). Foram utilizados os seguintes pesos econômicos: a) coeficiente de variação genético $(\mathrm{CVg})$; b) desvio padrão genético (DPg); c) herdabilidade $\left(\mathrm{h}^{2}\right)$; e d) valores atribuídos por tentativas (PT). As magnitudes dos valores de PT foram: 1, 1, 10, 10 e 1, valores atribuídos, respectivamente, para as características FIS, IPP, SOD, ST e SSB e considerados ótimos para obtenção de ganhos para a totalidade das características, obtidos, aleatoriamente, após atribuição de diversas grandezas. A primeira análise de variância foi efetuada utilizando o programa SAS (SAS Institute, 1997). As demais análises foram feitas utilizando o programa GENES (Cruz, 2006).

Baseando-se no melhor índice, foram selecionadas as dez melhores progênies. Dentro de cada progênie selecionada foi realizada uma seleção nos diferentes sexos (masculino e feminino). Dentro de cada progênie, selecionou-se uma planta masculina com menores valores para as variáveis analisadas. As dez plantas masculinas selecionadas permaneceram em campo em esquema de polinização aberta. Por outro lado, dentro de cada progênie, selecionaram-se as duas melhores plantas femininas, totalizando 20 futuras progênies. Dos frutos de tais plantas coletaram-se sementes para iniciar mais um ciclo de seleção, como sugerido por Vivas et al. (2012).

\section{RESULTADOS E DISCUSSÃO}

Como as progênies utilizadas neste trabalho foram derivadas de genótipos dióicos, houve a segregação dos indivíduos para o sexo. Assim, existiam plantas masculinas e femininas nas progênies avaliadas. Na análise de variância conduzida hierarquizando sexo dentro de progênie, não foi observado efeito significativo do sexo das plantas para nenhuma das cinco características avaliadas (Tabela 1). Tal fato permite que as inferências feitas nas progênies possam ser utilizadas para selecionar genótipos independentes do sexo dos indivíduos. As análises de variância evidenciaram diferença entre as progênies testadas para FIS, SPP, SSF e SSB em nível de $5 \%$ de probabilidade, pelo teste $\mathrm{F}$ (Tabela 1), indicando haver variabilidade genética para a resistência ao patógeno entre as progênies oriundas dos genótipos crioulos. Tal fato já havia sido observado por Vivas et al. (2012). Os mesmos autores observaram ainda diferenças nas magnitudes dos parâmetros genéticos estimados para as características supracitadas. Ademais, o teste de comparação de média dos genótipos efetuado por Vivas et al. (2012), torna difícil a seleção das dez progênies. Cada característica indica progênies distintas, dificultando a identificação das superiores. Visando suprir esta necessidade, a utilização de um índice, além de permitir a seleção das dez melhores progênies, oferece maior robustez, pois são agregadas as diferentes formas de avaliação da doença em um único índice. Tal metodologia já foi adotada por outros autores (Paula et al., 2002; Granate et al., 2002; Freitas Junior et al., 2009; Rangel et al., 2011). Recentemente, esta metodologia foi utilizada em mamoeiro (Ide, 2008). Entretanto, esta é a primeira vez que se utiliza de índice de seleção para auxiliar no processo de tomada de decisão relativo à escolha das melhores progênies quanto à resistência genética à doença em mamoeiro.

No presente estudo, observou-se que os ganhos percentuais preditos para o índice de seleção de Smith (1936) e Hazel (1943) permitiram simultaneamente a obtenção de ganhos negativos para SPP, SSF e SSB, bem como ganhos positivos para FIS. Para este índice, a melhor distribuição de ganho percentual predito foi obtida quando o peso econômico foi atribuído por tentativas (PT) (Tabela 2). Por outro lado, embora, o índice de Pesek \& Baker (1969) tenha proporcionado o maior ganho para FIS, proporcionou um dos menores ganhos para SPP, SSF e SSB (Tabela 2). Resultado diferente deste foi obtido por Paula et al. (2002), quando os autores, comparando os ganhos totais preditos por diferentes critérios de seleção aplicadas em progênies de Eucalyptus camaldulensis, determinaram que o índice de Pesek \& Baker (1969) proporciona resultados semelhantes aos de outros critérios de seleção empregados.

TABELA 1 - Resultados da análise de variância das avaliações de pinta-preta em progênies de mamoeiro, para as variáveis: número (posição) da primeira folha a iniciar o sintoma de pinta-preta (FIS, ud.), incidência de pinta-preta (IPP, \%), severidades de pinta-preta (SPP, \%) e reação à pinta-preta em folha (SSF, unid.; SSB, unid.)

\begin{tabular}{|c|c|c|c|c|c|c|}
\hline \multirow[t]{2}{*}{ Fonte de variação } & \multirow{2}{*}{$\begin{array}{l}\text { Graus de } \\
\text { liberdade }\end{array}$} & \multicolumn{5}{|c|}{ Quadrado médio } \\
\hline & & FIS & IPP & SSF & SPP & SSB \\
\hline Bloco & 5 & 2,044 & 117,873 & 0,494 & 0,499 & 0,750 \\
\hline Progênie & 23 & $1,361^{*}$ & $26,498^{\mathrm{ns}}$ & $1,517 * *$ & $1,367^{*}$ & $0,855^{\mathrm{ns}}$ \\
\hline Sexo (Progênie) & 24 & $0,864^{\mathrm{ns}}$ & $22,361^{\mathrm{ns}}$ & $0,377^{\mathrm{ns}}$ & $0,730^{\mathrm{ns}}$ & $0,560^{\mathrm{ns}}$ \\
\hline Resíduo & 91 & 0,773 & 29,957 & 0,485 & 0,859 & 0,892 \\
\hline Média & & 4,097 & 76,74 & 2,306 & 1,077 & 2,167 \\
\hline Coeficiente de variação (\%) & & 21,46 & 7,132 & 30,21 & 86,04 & 43,58 \\
\hline
\end{tabular}

*,** Significativo, respectivamente, em nível de 5 e $1 \%$ pelo teste $\mathrm{F},{ }^{\text {ns }}$ não significativo pelo teste $\mathrm{F}$. 
TABELA 2 - Estimativas de ganhos percentuais por seleção simultânea obtida pelos índices de Smith (1936) e Hazel (1943), Pesek \& Baker (1969), Williams (1962), e Mulamba \& Mock (1978), com base em quatro critérios de pesos econômicos para características relacionadas à resistência à pinta-preta avaliadas em progênies de meios-irmãos oriundas de genótipos crioulos de mamoeiro

\begin{tabular}{|c|c|c|c|c|c|c|}
\hline \multirow[t]{2}{*}{ Método } & \multirow[t]{2}{*}{ Pesos econômicos } & \multicolumn{5}{|c|}{ Ganho percentual estimado $(\%)$} \\
\hline & & FIS $^{(2)}$ & IPP & SSF & SPP & SSB \\
\hline \multirow[t]{4}{*}{ Smith \& Hazel } & $\mathrm{CVg}^{(1)}$ & 1,9 & 0 & $-13,73$ & $-11,37$ & $-0,29$ \\
\hline & DPg & 0,71 & 0 & $-12,73$ & $-10,17$ & $-0,26$ \\
\hline & $\mathrm{h}^{2}$ & 0,71 & 0 & $-12,73$ & $-10,17$ & $-0,26$ \\
\hline & PT & 2,58 & 0 & $-13,23$ & $-13,33$ & $-0,29$ \\
\hline \multirow[t]{4}{*}{ Pesek \& Baker } & $\mathrm{CVg}$ & 4,28 & 0 & $-8,21$ & $-9,95$ & $-0,23$ \\
\hline & DPg & 4,28 & 0 & $-8,21$ & $-9,95$ & $-0,23$ \\
\hline & $h^{2}$ & 4,28 & 0 & $-8,21$ & $-9,95$ & $-0,23$ \\
\hline & PT & 4,28 & 0 & $-8,21$ & $-9,95$ & $-0,23$ \\
\hline \multirow[t]{4}{*}{ Williams } & $\mathrm{CVg}$ & 3,26 & 0 & $-12,73$ & $-16,4$ & $-0,56$ \\
\hline & DPg & 2,58 & 0 & $-15,24$ & $-12,11$ & $-0,44$ \\
\hline & $\mathrm{h}^{2}$ & 2,58 & 0 & $-15,24$ & $-12,11$ & $-0,44$ \\
\hline & PT & 2,92 & 0 & $-13,73$ & $-15,32$ & $-0,5$ \\
\hline \multirow[t]{4}{*}{ Mulamba \& Mock } & $\mathrm{CVg}$ & 3,26 & 0 & $-12,73$ & $-16,4$ & $-0,56$ \\
\hline & DPg & 3,94 & 0 & $-7,7$ & $-13,11$ & $-0,56$ \\
\hline & $h^{2}$ & 3,6 & 0 & $-6,7$ & $-10,28$ & $-0,41$ \\
\hline & PT & 3,09 & 0 & $-11,72$ & $-15,0$ & $-0,56$ \\
\hline
\end{tabular}

(1) CVg = coeficiente de variação genético; DPg = desvio-padrão genético; $\mathrm{h}^{2}=$ herdabilidade; e PT = pesos atribuídos por tentativas (1, $\left.1,10,10,1\right)$. (2) FIS (unid.) = Folha a iniciar o sintoma de pinta-preta; IPP (\%) = incidência de folhas com sintoma de pinta-preta; SPP = severidade da pintapreta, segundo escala diagramática de Vivas et al. (2011); e, SSF e SSB = reações a pinta-preta em folha de acordo com metodologias de Santos Filho et al. (2007) e Santos \& Barreto (2003), respectivamente.

Por meio do índice de Williams (1962), observaramse ganhos genéticos em todos os critérios adotados (Tabela 2), sendo que a melhor distribuição de ganhos percentuais ocorreu quando se utilizou como peso econômico o $\mathrm{CVg}$ e o PT (Tabela 2). A distribuição de ganhos obtidas no presente estudo é conflitante com as obtidas por Granate et al. (2002). Os autores, ao utilizar o CVg como peso econômico em milho-pipoca, com auxílio do índice de Williams (1962), concluíram que esse coeficiente não permitia a obtenção de estimativas de ganhos preditos simultâneos nas características de maior interesse nesta cultura. Por outro lado, em outro estudo onde se comparou a eficiência de vários índices de seleção e de seus ganhos preditos no melhoramento para resistência ao frio em duas populações de milho, observou-se que os índices de seleção de Mulamba $\&$ Mock (1978) e de Williams (1962) ficaram entre os que propiciaram os melhores ganhos em todas as características avaliadas (Crosbie et al., 1980). Assim como observado por Crosbie et al. (1980), no presente estudo observou-se que o procedimento de Mulamba \& Mock (1978), bem como, o índice de seleção proposto por Williams (1962) foram os índices que proporcionaram as melhores distribuições de ganhos percentuais, quando foi adotado o critério $\mathrm{CVg}$ como peso econômico (Tabela 2), no que se refere à análise das estimativas de ganhos preditos. Observou-se também que os índices de Mulamba \& Mock (1978) e Williams (1962) foram os que proporcionaram os maiores ganhos percentuais quanto ao conjunto predito, quando foi adotado o critério $\mathrm{CVg}$ como peso econômico (Tabela 3).

A relação das progênies selecionadas e o ganho percentual total obtido para cada índice de seleção e peso econômico adotado estão presentes na Tabela 3. Observa-se que quando as progênies foram selecionadas empregando o CVg como peso econômico para critério de seleção, os métodos de Mulamba \& Mock (1978) e Williams (1962) apontaram as mesmas progênies. Estas progênies, quando selecionadas, apresentaram o maior ganho percentual predito (Tabela 3); além disso, proporcionaram ganhos satisfatórios em quatro características (FIS, SPP, SSF e SSB) (Tabela 2).

Com base nos critérios de Mulamba \& Mock (1978) e Williams (1962), foram selecionadas as progênies: 'STA02', 'STA-04', 'STA-05', 'STA-08', 'STA-13', 'STA-15', 'STA-16', 'STA-17', 'STA-22' e 'STA-24', as quais são apresentadas, juntamente com as médias da população original e população selecionada (Tabela 4). Pelos dados apresentados, observou-se redução para SPP, SSF e SSB. Para FIS houve um aumento da média, o que significa que a próxima geração tende a apresentar maior número de folhas sem sintomas de pinta-preta, ou que a doença vai ocorrer mais tardiamente na planta, o que é desejável. Já, para incidência, houve um ligeiro incremento, sendo este considerado indesejável. Tal fato já era esperado, uma vez que Vivas et al. (2012), estimando parâmetros genéticos para estas progênies, observou baixa variância genética e forte efeito ambiental para incidência de folhas com pintapreta.

Considerando que a população de trabalho se originou de genótipos dióicos, houve a segregação das plantas para sexo (masculino e feminino). Como se observou que esta diferenciação não interfere na resistência da progênie aos diferentes componentes de resistência à pinta-preta (Tabela 
TABELA 3 - Métodos de Smith (1936) e Hazel (1943) (SH), Pesek \& Baker (1969) (PB), Williams (1962) (W), e Mulamba \& Mock (1978) (MM) adotados e pesos econômicos para seleção de progênies e ganho percentual estimados conjuntamente para as cinco características avaliadas em progênies de meios-irmãos oriundas de genótipos locais de mamoeiro

\begin{tabular}{|c|c|c|c|}
\hline Método & $\begin{array}{l}\text { Pesos } \\
\text { econômicos }\end{array}$ & Progênies selecionadas & $\begin{array}{c}\text { Ganho } \\
\text { total }(\%)\end{array}$ \\
\hline \multirow[t]{4}{*}{$\mathrm{SH}$} & $\mathrm{CVg}^{(1)}$ & $\begin{array}{l}\text { 'STA-02', 'STA-03', 'STA -04', 'STA -05', 'STA -08', 'STA -13', 'STA - } \\
14 \text { ', 'STA-16', 'STA-17' e 'STA-18'. }\end{array}$ & 27,29 \\
\hline & $\mathrm{DPg}$ & $\begin{array}{l}\text { 'STA-02', 'STA -03', 'STA -04', 'STA -05', 'STA -08', 'STA -13', 'STA - } \\
14 \text { ', 'STA-15', 'STA-17' e 'STA-18'. }\end{array}$ & 23,87 \\
\hline & $\mathrm{H}^{2}$ & $\begin{array}{l}\text { 'STA-02', 'STA -03', 'STA -04', 'STA -05', 'S TA-08', 'STA -13', 'STA - } \\
14 \text { ', 'STA-15', 'STA-17' e 'STA-18'. }\end{array}$ & 23,87 \\
\hline & $\mathrm{PT}$ & $\begin{array}{l}\text { 'STA-02,' 'STA -03', 'STA -04', 'STA -05', 'STA -08', 'STA -13', 'STA - } \\
14 \text { ', 'STA-16', 'STA-17' e 'STA-24'. }\end{array}$ & 29,43 \\
\hline \multirow[t]{4}{*}{ PB } & $\mathrm{CVg}$ & $\begin{array}{l}\text { 'STA-03', 'STA -04', 'STA -08', 'STA -10', 'STA -11', 'STA -13', 'STA - } \\
16 \text { ', 'STA-17', 'STA-22' e 'STA-24'. }\end{array}$ & 22,67 \\
\hline & $\mathrm{DPg}$ & $\begin{array}{l}\text { 'STA-03', 'STA -04, 'STA -08', 'STA -10', 'STA -11', 'STA -13', 'STA - } \\
16 \text { ', 'STA-17', 'STA-22' e 'STA-24'. }\end{array}$ & 22,67 \\
\hline & $\mathrm{H}^{2}$ & $\begin{array}{l}\text { 'STA-03', 'STA -04, 'STA -08', 'STA -10', 'STA -11', 'STA -13', 'STA - } \\
16 \text { ', 'STA-17', 'STA-22' e 'STA-24'. }\end{array}$ & 22,67 \\
\hline & PT & $\begin{array}{l}\text { 'STA-03', 'STA -04', 'STA -08', 'STA -10', 'STA -11', 'STA -13', 'STA - } \\
\text { 16', 'STA-17', 'STA-22' e 'STA-24'. }\end{array}$ & 22,67 \\
\hline \multirow[t]{4}{*}{$\mathrm{W}$} & $\mathrm{CVg}$ & $\begin{array}{l}\text { 'STA-02', 'STA -04', 'STA -05', 'STA -08, 'STA -13', 'STA -15', 'STA - } \\
16 \text { ', 'STA-17', 'STA-22' e 'STA-24'. }\end{array}$ & 32,95 \\
\hline & $\mathrm{DPg}$ & $\begin{array}{l}\text { 'STA-02,' 'STA -03', 'STA-04', 'STA -05', 'STA -08', 'STA -13', 'STA - } \\
15 \text { ', 'STA-16', 'STA-17' e 'STA-18'. }\end{array}$ & 30,37 \\
\hline & $\mathrm{H}^{2}$ & $\begin{array}{l}\text { 'STA-02', 'STA -03', 'STA -04', 'STA -05', 'STA -08', 'STA -13', 'STA - } \\
15 \text { ', 'STA-16', 'STA-17' e 'STA-18'. }\end{array}$ & 30,37 \\
\hline & PT & $\begin{array}{l}\text { 'STA-02', 'STA -04', 'STA -05', 'STA -08', 'STA -13', 'STA-15', 'STA - } \\
16 \text { ', 'STA-17', 'STA-18' e 'STA-24'. }\end{array}$ & 32,47 \\
\hline \multirow[t]{4}{*}{ MM } & $\mathrm{CVg}$ & $\begin{array}{l}\text { 'STA-02,', 'STA -04', 'STA -05', 'STA -08', 'STA -13', 'STA -15', 'STA - } \\
\text { 16', 'STA-17', 'STA-22' e 'STA-24' }\end{array}$ & 32,95 \\
\hline & $\mathrm{DPg}$ & $\begin{array}{l}\text { 'STA-02', 'STA -04', 'STA -08', 'STA -10', 'STA -12', 'STA -13', 'STA - } \\
\text { 16', 'STA-17', 'STA-22' e 'STA-24'. }\end{array}$ & 25,31 \\
\hline & $\mathrm{H}^{2}$ & $\begin{array}{l}\text { 'STA-02', 'STA -04', 'STA -06', 'STA -08', 'STA-10', 'STA-12', 'STA - } \\
13 \text { ', 'STA-16', 'STA-27' e 'STA-24'. }\end{array}$ & 20,99 \\
\hline & PT & $\begin{array}{l}\text { 'STA-02', 'STA -04', 'STA -05', 'STA -08', 'STA -12', 'STA -13', 'STA - } \\
15 \text { ', 'STA-16', 'STA-17' e 'STA-24'. }\end{array}$ & 30,37 \\
\hline
\end{tabular}

(1) $\mathrm{CVg}$ = coeficiente de variação genético; $\mathrm{DPg}=$ desvio-padrão genético; $\mathrm{h}^{2}=$ herdabilidade; e PT = pesos atribuídos por tentativas $(1,1,10,10,1)$.

TABELA 4 - Média dos híbridos, selecionados através do índice de Williams (1962)

\begin{tabular}{|c|c|c|c|c|c|}
\hline \multirow[t]{2}{*}{ Progênie selecionada } & \multicolumn{5}{|c|}{ Caráter avaliado } \\
\hline & FIS $^{(1)}$ & IPP & SSF & SPP & SSB \\
\hline 'STA-02' & 4,17 & 77,87 & 1,67 & 0,49 & 1,5 \\
\hline 'STA-04' & 4,33 & 78,79 & 1,83 & 1,02 & 1,83 \\
\hline 'STA-05' & 3,83 & 78 & 1,83 & 0,97 & 2 \\
\hline 'STA-08' & 4,67 & 72,89 & 2 & 0,5 & 1,83 \\
\hline 'STA-13' & 4,67 & 78,23 & 1,67 & 0,36 & 1,67 \\
\hline 'STA-15' & 4,17 & 76,02 & 2,17 & 0,9 & 2 \\
\hline 'STA-16' & 5,33 & 75,01 & 1,83 & 0,57 & 1,83 \\
\hline 'STA-17' & 4 & 79,91 & 1 & 0,13 & 1,83 \\
\hline 'STA-22' & 4,33 & 78,21 & 2,5 & 0,79 & 1,83 \\
\hline 'STA-24' & 4,67 & 76,06 & 2,33 & 0,55 & 2,17 \\
\hline Média geral das progênies selecionadas & 4,42 & 77,10 & 1,88 & 0,63 & 1,85 \\
\hline Média da população original & 4,10 & 76,74 & 2,31 & 1,08 & 2,17 \\
\hline
\end{tabular}


1), foi possível conduzir a seleção das dez progênies superiores considerando todas as plantas. Entretanto, tornase necessário proceder à seleção das plantas dentro das progênies para cada sexo.

Para plantas masculinas foram realizadas seleções dentro das progênies considerando os valores dos indivíduos dentro de cada progênie superior, deixando apenas um individuo masculino por progênie selecionada (Tabela 5). Por outro lado, dentro de cada progênie, selecionaram-se as duas melhores plantas femininas, totalizando 20 futuras progênies selecionadas (Tabela 6). Adotou-se no presente trabalho, como alternativa para prática da polinização, o esquema "policross", envolvendo apenas os indivíduos selecionados, uma vez que é o mais fácil de ser executado

TABELA 5 - Valores fenotípicos dos indivíduos selecionados dentro de cada progênie masculina

\begin{tabular}{|c|c|c|c|c|c|c|}
\hline \multicolumn{2}{|c|}{ Indivíduo selecionado } & \multicolumn{5}{|c|}{ Características avaliadas } \\
\hline Progênie & Bloco & $\mathbf{F I S}^{(1)}$ & IPP & SSF & SPP & SSB \\
\hline 'STA-02' & 3 & 3 & 84,62 & 1 & 0,01 & 1 \\
\hline 'STA-04' & 6 & 5 & 80,95 & 1 & 0,5 & 1 \\
\hline 'STA-05' & 2 & 4 & 81,25 & 1 & 0,03 & 1 \\
\hline 'STA-08' & 3 & 4 & 57,15 & 1 & 0,46 & 1 \\
\hline 'STA-13' & 6 & 5 & 82,61 & 1 & 0,03 & 1 \\
\hline 'STA-15' & 6 & 4 & 75,00 & 2 & 0,5 & 2 \\
\hline 'STA-16' & 4 & 6 & 77,27 & 1 & 0,4 & 1 \\
\hline 'STA-17' & 4 & 5 & 78,95 & 1 & 0,02 & 1 \\
\hline 'STA-22' & 5 & 4 & 81,25 & 2 & 0,4 & 2 \\
\hline 'STA-24' & 6 & 7 & 78,57 & 0 & 0 & 1 \\
\hline \multicolumn{2}{|c|}{ Média dos indivíduos selecionados } & 4,7 & 77,76 & 1,1 & 0,24 & 1,2 \\
\hline \multicolumn{2}{|c|}{ Média da população original } & 4,10 & 76,74 & 2,31 & 1,08 & 2,17 \\
\hline
\end{tabular}

${ }^{(1)}$ FIS (unid.) = Folha a iniciar o sintoma de pinta-preta; IPP (\%) = incidência de folhas com sintoma de pinta-preta; SPP = severidade da pintapreta, segundo escala diagramática de Vivas et al. (2011); e, SSF e SSB = reações a pinta-preta em folha de acordo com metodologias de Santos Filho et al. (2007) e Santos \& Barreto (2003), respectivamente.

TABELA 6 - Valores fenotípicos dos indivíduos selecionados dentro de cada progênie feminina

\begin{tabular}{|c|c|c|c|c|c|c|}
\hline \multicolumn{2}{|c|}{ Indivíduo selecionado } & \multicolumn{5}{|c|}{ Características avaliadas } \\
\hline Progênie & Bloco & $\mathbf{F I S}^{(1)}$ & IPP & SSF & SPP & SSB \\
\hline \multirow[t]{2}{*}{ 'STA-02' } & 2 & 5 & 73,33 & 1 & 0,8 & 1 \\
\hline & 6 & 6 & 75 & 1 & 0,05 & 2 \\
\hline \multirow[t]{2}{*}{ 'STA-04' } & 1 & 6 & 68,75 & 2 & 0,02 & 1 \\
\hline & 5 & 5 & 80,95 & 1 & 0,2 & 2 \\
\hline \multirow[t]{2}{*}{ 'STA-05' } & 5 & 5 & 66,67 & 1 & 0,5 & 2 \\
\hline & 6 & 4 & 80,83 & 2 & 1,03 & 2 \\
\hline \multirow[t]{2}{*}{ 'STA-08' } & 4 & 5 & 70,72 & 2 & 0,47 & 2 \\
\hline & 5 & 7 & 76,92 & 1 & 0,02 & 1 \\
\hline \multirow[t]{2}{*}{ 'STA-13' } & 1 & 5 & 74,61 & 2 & 0,56 & 2 \\
\hline & 5 & 6 & 75 & 1 & 0,05 & 1 \\
\hline \multirow[t]{2}{*}{ 'STA-15' } & 1 & 5 & 69,23 & 2 & 0,05 & 1 \\
\hline & 5 & 5 & 83,33 & 1 & 0,2 & 1 \\
\hline \multirow[t]{2}{*}{ 'STA-16' } & 1 & 5 & 69,23 & 2 & 0,8 & 2 \\
\hline & 3 & 5 & 75,9 & 2 & 0,53 & 2 \\
\hline \multirow[t]{2}{*}{ 'STA-17' } & 5 & 5 & 75 & 1 & 0,03 & 1 \\
\hline & 6 & 4 & 86,96 & 1 & 0,1 & 2 \\
\hline \multirow[t]{2}{*}{ 'STA-22' } & 3 & 6 & 66,67 & 2 & 0,01 & 1 \\
\hline & 6 & 5 & 81,04 & 2 & 0,85 & 2 \\
\hline \multirow[t]{2}{*}{ 'STA-24' } & 2 & 4 & 75 & 3 & 1,2 & 3 \\
\hline & 3 & 4 & 80 & 1 & 0,3 & 2 \\
\hline \multicolumn{2}{|c|}{ Média dos indivíduos selecionados } & 5,10 & 75,26 & 1,55 & 0,39 & 1,65 \\
\hline \multicolumn{2}{|c|}{ Média da população original } & 4,10 & 76,74 & 2,31 & 1,08 & 2,17 \\
\hline
\end{tabular}

(1)FIS (unid.) = Folha a iniciar o sintoma de pinta-preta; IPP (\%) = incidência de folhas com sintoma de pinta-preta; SPP = severidade da pintapreta, segundo escala diagramática de Vivas et al. (2011); e, SSF e SSB = reações a pinta-preta em folha de acordo com metodologias de Santos Filho et al. (2007) e Santos \& Barreto (2003), respectivamente. 
em campo e por dispensar o controle manual da polinização. Para indivíduos selecionados, observou-se redução nas médias para SSF, SPP e SOD nas plantas masculinas, quando comparada com a média da população original (Tabela 5). Resultado semelhante foi observado entre as plantas femininas (Tabela 6), o que pode ser indicativo de um maior incremento no ganho de resistência à pinta-preta na próxima geração.

\section{AGRADECIMENTOS}

À Fundação de Amparo à Pesquisa do Estado do Rio de Janeiro - FAPERJ e à Universidade Estadual do Norte Fluminense Darcy Ribeiro - UENF, pelo suporte financeiro e logístico.

\section{REFERÊNCIAS BIBLIOGRÁFICAS}

Crosbie TM, Mock JJ, Smith OS (1980) Comparison of gains predicted by several methods for cold tolerance traits of two maize populations. Crop Science 20:649-655.

Cruz CD (2006) Programa Genes: Biometria. Viçosa MG. Editora UFV.

Freitas Junior, SP, Rangel RM, Viana AP, Amaral Junior AT (2009) Predição de ganhos genéticos na população de milho pipoca UNB2U sob seleção recorrente utilizando-se diferentes índices de seleção. Ciências Agrárias 30:803-814.

Granate MJ, Cruz CD, Pacheco CAP (2002) Predição de ganho genético com diferentes índices de seleção no milhopipoca CMS-43. Pesquisa Agropecuária Brasileira 37:101-108.

Hazel LN (1943) The genetic basis for constructing selection indexes. Genetics 28:476-490.

Ide CD (2008) Melhoramento genético do mamoeiro (Carica papaya L.): Parâmetros genéticos e capacidade combinatória em ensaios de competição de cultivares. Tese de Doutorado, Universidade Estadual do Norte Fluminense Darcy Ribeiro (UENF). Campos dos Goytacazes RJ.

Marin SLD, Gomes JA, Salgado JS, Martins DS, Fullin EA (1995) Recomendações para a cultura do mamoeiro dos grupos Solo e Formosa no Estado do Espírito Santo. 4 ed. Vitória ES. Emcapa. (Circular Técnica no. 3).

Medeiros LAM, Balardin RS, Costa IFD, Gulart CA, Lenz G (2008) Reação de germoplasma crioulo de feijoeiro (Phaseolus vulgaris L.) a Colletotrichum lindemuthianum. Tropical Plant Pathology 33:273280

Mulamba NN, Mock JJ (1978) Improvement of yield potential of the Eto Blanco maize (Zea mays L.) population by breeding for plant traits. Egypt Journal of Genetics and Cytology 7:40-51.

Nishijima WT, Dicman MB, Ho WH, Ooka JJ (1994) Papaya diseases causes by fungi. In: Ploetz RC, Zentmyer GA, Nishijima WT, Rohrbach KG, Ohr HD (Eds.) Compendium of tropical fruit diseases. St. Paul MN, EUA. APS Press. pp. 58-64.

Oliveira EJ, Amorim VBO, Matos ELS, Costa JL, Castellen MS, Pádua JG, Dantas JLL (2010) Polymorphism of microsatellite markers in papaya (Carica papaya L.). Plant Molecular Biology Reporter 28:519-530.

Paula RC, Pires IE, Borges RCG, Cruz CD (2002) Predição de ganhos genéticos em melhoramento florestal. Pesquisa Agropecuária Brasileira 37:159-165.

Pesek J, Baker RJ (1969) Desired improvement in relation to selection indices. Canadian Journal of Plant Sciences 1:215-274.

Rangel RM, Amaral Júnior AT, Gonçalves LSA, Freitas Júnior SP, Candido LS (2011) Análise biométrica de ganhos por seleção em população de milho pipoca de quinto ciclo de seleção recorrente. Revista Ciência Agronômica 42:473-481.

Rezende JAM, Martins MC (1997) Doenças do mamoeiro (Carica papaya L.). In: Kimati H, Amorim L, Rezende JAM, Bergamin Filho A, Camargo LEA(Eds.) Manual de fitopatologia: Doenças das plantas cultivadas. São Paulo SP. Agronômica Ceres. pp. 435-443.

Santos Filho HP, Oliveira AAR, Noronha ACS, Sanches NF, Lopes FF, Andrade PRO, Osório ACB, Souza JA, Oliveira AMG, Santos MJ (2007) Monitoramento e controle da pinta-preta do mamoeiro. Cruz das Almas BA. Embrapa Mandioca e Fruticultura Tropical. (Comunicado Técnico no. 125).

Santos MC, Barreto M (2003) Estudo epidemiológico da varíola do mamoeiro em cultivares submetidos a tratamento com fungicidas. Summa Phytopathologica 29:141-146.

SAS Institute (1997) SAS/STAT software: changes and enhancements through release 6.12. Cary NC, EUA. SAS Institute.

Serrano LAL, Cattaneo LFO (2010) O cultivo do mamoeiro no Brasil. Revista Brasileira de Fruticultura 2010, vol. 32, n.3.

Smith HF (1936) A discriminant function for plant selection. Annals of Eugenics 7:240-250.

Theodoro GF (2004) Reação de cultivares locais de feijão a Xanthomonas axonopodis pv. phaseoli, em condições de campo. Revista Brasileira de Agrociência 10:373-375.

Vilarinho AA, Viana JMS, Santos JF, Câmara TMM (2003) Eficiência da seleção de progênies $\mathrm{S} 1$ e S2 de milho pipoca, visando à produção de linhagens. Bragantia 62:9-17.

Vivas M (2009) Avaliação de germoplasma e híbridos de mamoeiro quanto à resistência a doenças causadas pelos fungos Asperisporium caricae, Colletotrichum gloeosporioides, Oidium caricae e Phoma caricae-papayae. Dissertação de Mestrado, Universidade Estadual do Norte Fluminense Darcy Ribeiro (UENF). Campos dos Goytacazes RJ.

Vivas M, Silveira SF, Terra CEPS, Pereira MG (2010) Reação de germoplasma e híbridos de mamoeiro à mancha-de-phoma (Phoma caricae-papayae) em condições de campo. Tropical Plant Pathology $35: 323-328$.

Vivas M, Silveira SF, Terra CEPS, Pereira MG (2011) Testers for combining ability and selection of papaya hybrids resistant to fungal diseases. Crop Breeding and Applied Biotechnology 11:36-42.

Vivas M, Silveira SF, Vivas JMS, Pereira MG (2012) Patometria, parâmetros genéticos e reação de progênies de mamoeiro à pintapreta. Bragantia 71:235-238.

Willians JS (1962) The evaluation of a selection index. Biometrics 18:375-393. 